\title{
THE DIGITAL ACADEMY
}

\author{
PREPARING FACULTY FOR DIGITAL COURSE \\ DEVELOPMENT
}

Sunay V. Palsole, Beth L. Brunk-Chavez,
University of Texas at El Paso

New generations of learners necessitate new ways of teaching, and bybrid courses can help institutions leverage technologies to improve teaching and learning. The adoption of a new instructional paradigm, however, requires attention to the faculty's ability to create and deliver effective courses. The University of Texas at El Paso has developed the Digital Academy to belp faculty interweave online elements with face-to-face teaching. The model is pliable and portable in its application to other universities.

University educators are challenged to engage and educate a generation of learners who were born into the digital age, grew up with digital technologies readily available, think and learn very differently from previous generations of students, and are highly engaged with technology in multiple ways (Howe \& Strauss, 2000; Palfrey \& Gasser, 2008; Tapscott, 1999). Given the technological attitudes and experiences of the digital generation, it is no surprise that these students enter universities with significant expectations regarding the use of technology to support their learning. However, students' expectations of learning anywhere, anytime, and with a variety of technological tools may exceed their instructors' abilities to use technology innovatively and effectively (Roberts, 2005). At the same time, universities are experiencing growing enrollments and therefore an increasing demand for classroom space, putting tremendous pressure on them to meet scheduling demands.

These dual demands of shifting student learning styles and limited space are certainly challenging, but they also generate an opportunity for 
faculty developers to work with instructors toward creatively and efficiently transforming the delivery of university courses while continuing to maintain high academic standards. Much can be achieved by rethinking traditional classroom spaces and replacing face time by leveraging various technologies to deliver content and encourage interaction online (National Center for Academic Transformation, 2005). One solution is to move selected courses into a hybrid environment. Hybrid, or blended, delivery combines the best features of online learning and faceto-face teaching (Sands, 2002). Although variations are possible, students enrolled in hybrid courses generally meet one day a week in a classroom and shift a significant portion of the work into an online environment such as a course management system or wiki. Therefore, hybrid delivery of courses enables universities to reduce the need for classroom space by 50 percent or more and provide students with the opportunity to learn in a more flexible anytime, anywhere environment.

\section{The Challenges of Shifting to Hybrid Delivery}

While campuses embrace the multiple benefits that hybrid courses provide, the reality is that many college faculty are not prepared to teach in this blended environment. They are content specialists but not yet "computer-empowered users," whom Selber (2004) described as being able to "integrate computers ... productively, and [to] cope reasonably well in dynamic environments" (p. 46). Instructors need to be computer-empowered users who can "confront skill demands, collaborate online, and explore instructional opportunities" (Selber, 2004, p. 46). Therefore, faculty developers can play an integral role in gauging the technological literacies of faculty who are sometimes intimidated by learning new technologies or have difficulty translating what they do well in the physical classroom to an online environment. In addition, instructors who are empowered users in the traditional classroom often learn that these strengths alone are not sufficient for making the transition to a hybrid course. To teach a successful hybrid class, instructors need to do more than know how to use technology. They must also reenvision their instruction and be willing to replace the traditional sage-on-stage approach with more student-centered pedagogy.

Cho and Berge (2002) identified major barriers that most faculty face when creating and delivering hybrid or online courses, no matter what their comfort level with technology, including administrative structure, evaluation of effectiveness, quality of social interaction, student support 
services, access, faculty compensation, time, and legal issues. When moving a traditional class to a hybrid environment, such obstacles can become a great source of frustration for instructors. The Digital Academy, a series of faculty engagement and training workshops that immerses instructors in the course model they are developing, can help alleviate these frustrations. By assuming the roles of both instructor and student within the Academy, faculty can become comfortable in the design and delivery of their own hybrid courses.

\section{The Digital Academy}

Since the early 2000s, many outstanding articles and books have been published to assist faculty in making the transition from face-to-face to hybrid courses, and many studies have helped us understand what pedagogies and online tools work most effectively. Although these are useful on their own, collectively they form a disparate bundle of information that needs to be brought together as a cohesive, structured whole. So when faculty at the University of Texas at El Paso expressed interest in teaching hybrid courses, instructional support services (ISS) saw value in creating a community of faculty learners who work together to design, develop, and eventually deliver hybrid courses. The Academy was formed, and in order to ensure effective teaching, the provost's office required that all faculty new to hybrid courses participate.

One of the initial steps was for ISS faculty developers to create a general framework and guiding principles for hybrid courses at our university. Academy participants learn that no matter the discipline, hybrid courses should not be run as two separate and distinct teaching environments. Rather, the face-to-face and online activities, engagements, and learning strands should interweave and inform one another. The work students do in class should directly relate to and inform the work students do online, and vice versa; the two modes of instruction must be truly blended.

In addition, we determined that instructors need support in embracing and implementing student-centered instruction, effective and timely intervention and feedback, peer-to-peer interaction, and multiple input sources within a highly interactive learning context. The success of a hybrid course depends on an instructional design that supports specific learning outcomes, allows flexible delivery, and encourages both student and instructor participation (Dudeney, 2001; Laird, 2003; Sharp, 2005). Establishing these general principles from the start enabled ISS faculty developers to determine goals for the Academy. 


\section{Academy Goals}

Based on our hybrid framework and general principles, the central goals of the Academy are to help participants organize and then prepare to deliver hybrid courses in their program. To do this, the Academy focuses on four subgoals of assisting faculty:

- Modifying and applying teaching techniques for hybrid environments

- Applying practical knowledge of basic courseware management environments

- Developing strategies to engage students in a hybrid setting

- Developing effective student assessments for hybrid learning

\section{Academy Participants}

Each Digital Academy enrolls between eight and twelve participants. The first Academies were focused on specific programs such as first-year composition and the entering student program because there was a critical mass of interested instructors within these programs. While we initially felt that having participants with similar backgrounds would be productive, the Academies were altered when we realized that having a broad mix of backgrounds led to more robust and open feedback. Current Academies are run using an open call for proposals, so faculty from education may be in an Academy along with engineering, liberal arts, and science faculty. Participants have reported that they enjoyed meeting and networking with colleagues from different colleges and backgrounds, and they felt that they received valuable feedback on their instructional design and interactivities when paired with someone who was not familiar with their field of expertise.

\section{Academy Content}

Instructional tasks and readings vary depending on the strengths, weaknesses, disciplinary focus, and experience of the participants, but each Academy generally covers the following topics:

- Building content: Writing content for and with digital media; using the tools within the learning management system; using external tools; chunking content

- Considering copyright: Understanding copyright concerns and rules when distributing content in digital formats 
- Building an effective course syllabus: Identifying key learning outcomes; uncovering hidden goals; providing a structure for class. performance and rules

- Selecting technology: Experiencing different technologies and adapting technologies to achieve desired outcomes; evaluating technologies; considering student-driven adoption strategies

- Mapping the course: Approaching the course from a student perspective; creating visual maps of the course and identifying gaps in goals, assessments, and content; creating navigation schema for students

- Encouraging student engagement: Developing strategies for engaging students in online and face-to-face environments; connecting in-class activities to online activities and vice versa; considering alternative assessments, reward structures, and competition within the classroom; establishing instructor presence in online settings; using Web 2.0 tools (Twitter, Facebook) to create a social network within the course

- Developing assessments: Writing effective assessments to measure learning outcomes; developing formative and summative assessments; adopting a culture of assessment; adopting various assessment tools in a learning management system; using external applications (Articulate, StudyMate)

- Managing the course: Developing effective strategies to handle student concerns; considering workload issues and time constraints; setting course management goals; cycling student feedback into a continuous improvement loop; creating time lines for course updates; creating efficiencies using the grade book tool

\section{Academy Structure}

With such a robust list of goals, the first versions of the Academy consisted of two face-to-face workshops a month for one semester. However, we realized that this format created a significant disconnect for participants and that they required several follow-up sessions on both pedagogical strategies and technologies for course creation. Faculty developers felt that participants would be more engaged in the content of the workshops if they were offered in a compressed format and if more of the work were completed online. In addition, we determined that offering compressed Digital Academies for a week while classes were not in session would 
Figure 2.1 The Digital Academy Model

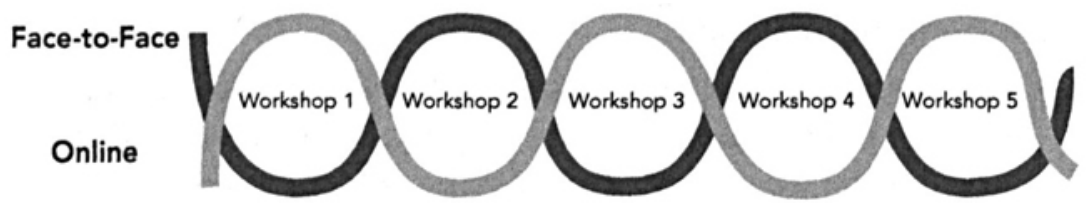

allow participants to focus on course redesign instead of being distracted by their current teaching and grading responsibilities.

Although the Academy was compressed, the intensity of the interaction allowed faculty developers to expand the topics addressed and better integrate the theoretical with the practical. Reshaping the format to more closely reflect a hybrid course ( 50 percent face-to-face and 50 percent online) helped participants understand the student experience of being enrolled in one. The Academy now weaves the two seemingly disparate but complementary elements of hybrid courses to save time and model the experience. Figure 2.1 illustrates how the workshops interweave the face-to-face and online components.

In this compressed hybrid model, participants meet for five hours a day Monday through Friday. During the morning, instructors first participate in an "experience session" when they experience different interactions (content modules, crossword interactions, Webquests, and so on) that students may also experience in a hybrid course. These activities are designed to get participants thinking about student engagement and course design. The experience session is followed by a "think session," which addresses the pedagogical and theoretical aspects of course redesign. During this time, instructors are engaged in the previously assigned readings through active discussions in a face-to-face classroom setting. They are also given the assignment of redesigning existing elements of their face-to-face course by considering a variety of potential technological tools and then gathering feedback from their peers in the Academy.

The afternoon "learning the technology sessions" are spent discussing and applying technologies needed to achieve outcomes identified in the morning sessions. To integrate face-to-face meetings with online work, participants are given time to engage in online portions of the Academy course at the end of the session. They then have homework to complete before the next class meeting. Often this is a reading assignment followed by online discussions, as well as creation of one element in their new hybrid course module. By continuing through this cycle, participants 
Figure 2.2 One Day in the Digital Academy

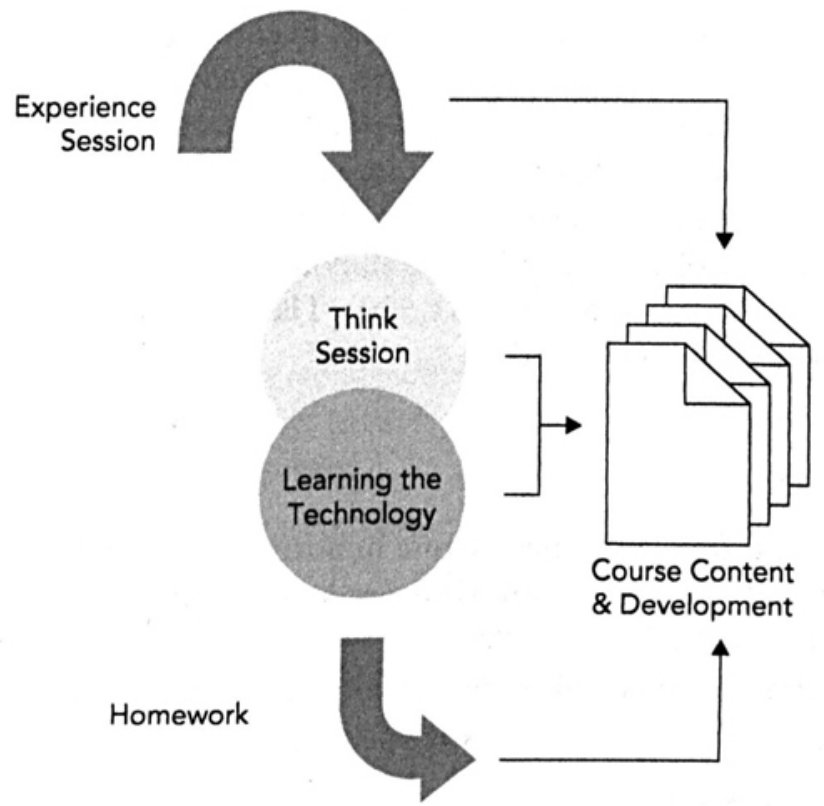

build at least one complete course module that includes content, engagement exercises, and discussion questions. To test the efficacy of the modules as they are being developed, at least two other Academy participants are enrolled as students within them and are asked to provide feedback. This feedback is then cycled into the development loop, thus leading to the improved quality of the module before it is delivered inside a hybrid course. Figure 2.2 illustrates each day's structure.

Although each Academy is designed to attain similar goals, the schedule and focus may change based on participant preparedness and experience with formal course design principles and technology use. The level of technology instruction and application is made more complex if most of the incoming participants are fairly comfortable with technology and are empowered users. This ensures a learning environment no matter what level of expertise participants have before the Academy begins.

\section{Academy Completion}

The end result of the Academy is that each participant creates a course module to be evaluated using the framework outlined by Chickering and Ehrmann (1996). The Academy emphasizes the principles of contact 
between students and faculty, reciprocity and cooperation among students, use of active learning techniques, high expectations, and respect for diverse talents and ways of learning. Beginning in the semester following the Academy, participants are expected to teach at least two technology-enhanced courses (less than 50 percent online), followed by fully hybrid courses ( 50 percent or more online) in successive semesters. Academy participants receive various incentives for completion including stipends $(\$ 1,000$ to $\$ 1,500)$, travel money $(\$ 500)$, or new computers (ranging in price from $\$ 750$ to $\$ 1,500$ ). The incentive is awarded after the hybrid course is delivered.

\section{Outcomes}

Over the past five years, nearly one hundred faculty have participated in the Digital Academies offered every summer and during some winter intersessions. We have collected a variety of data and feedback from Academy participants and students enrolled in their classes.

\section{Faculty Feedback}

Eighty-seven faculty responded to the feedback survey. Approximately 83 percent felt that the experience expanded their knowledge about hybrid courses, and 93 percent felt that the Academy prepared them to develop and effectively teach their own hybrid courses. Seventy percent of participants expressed confidence in their ability to teach with technology to the extent that they forwent the technology-enhanced course and taught a hybrid course immediately. We gathered the following answers from the questions on the survey instrument:

- "Before participating in the Academy, my knowledge of teaching online, hybrid, and technology-enhanced courses could best be classified as":

None: 21 percent

Introductory: 0 percent

Moderate: 43 percent

Extensive: 23 percent

- "After participating in the Academy, my practical knowledge about teaching online, hybrid, and technology-enhanced courses satisfactorily increased." 
Strongly agree: 49 percent

Agree: 23 percent

Disagree: 5 percent

Strongly disagree: 0 percent

- "The Academy effectively taught me the following about teaching online, hybrid, and technology-enhanced courses, and these things helped me in developing and teaching my course(s) (check all that apply)."

How to rewrite course objectives that can be effectively achieved in an online, hybrid, and technology-enhanced course environment: 67 percent

How to implement some digital tools (for example, software, hardware, Web 2.0 tools) to promote active learning: 85 percent

How to develop authentic assessments of student learning for online delivery: 51 percent

How to engage students online and build an online learning community: 74 percent

How to plan the structure and content in an online, hybrid, and technology-enhanced course: 78 percent

How to structure my course so that I can use the tools to improve my efficiency and balance instructor presence in the course with use of instructor's time: 69 percent

In addition to survey data, success of the Academy is illustrated through the following statements from Academy participants. A lecturer in history said: "The Academy really helped me see that my subject-which I thought really needed me in the classroom to be successful-could be changed to reduced class time and actually enhance the student learning. I can be a bit more creative with their assignments, which has made this interesting for the students and me." An education professor felt that the process of formally creating a hybrid course caused her to redesign her face-to-face courses to incorporate more online elements.

Finally, faculty satisfaction is borne out by the increased number of hybrid courses offered on campus. We believe that if Academy participants were not satisfied with the courses, they would not continue to teach them or encourage others to do so. The total number of officially scheduled hybrid courses has increased from 13 sections in academic year 2004-2005 to more than 250 in 2009-2010. We have also noticed 
an increase in the offerings of technology-enhanced courses: more than eighteen hundred sections in academic year 2009-2010. Informal data collected from faculty who offer these courses suggest that this may be the result of Academy participants' encouraging their colleagues to teach with technology.

\section{Student Feedback}

While instructor satisfaction and increased offerings are important measures, the success of the Academy is ultimately measured in terms of student satisfaction and learning. Therefore, we include student surveys in our feedback loop to help inform future iterations of the Academy. Surveys have measured student comfort levels with software applications, as well as general anxieties about use of technology in the classroom. Surveys also measured student reactions to the hybrid course format. Initial outcomes indicated that over 85 percent of students surveyed would take hybrid courses again, and over 90 percent of those same students would recommend that other students take hybrid courses. Qualitative data gathered with the student surveys suggest that students experience an increase in both knowledge and comfort with technology, in particular the learning management system and other classroom technologies. Informal student data collected from students in hybrid courses and analysis of the grade spread in hybrid courses compared to face-to-face classes suggest that hybrid courses are as engaging as face-to-face classes, with no significant differences in learning outcomes and grade spread. Follow-up data that analyzed student writing in all of the writing courses suggest that student retention and quality of reflective work are better in hybrid than in face-to-face courses.

\section{Overall Outcomes}

Some academic units such as the first-year composition program, developmental English, and education have found hybrids to be so successful that they now offer all sections of specific courses as hybrids to improve the students' technological literary and save on classroom space. For example, all sections of the first-year composition course-more than ninety of them-can be taught in existing computer lab spaces instead of in the more tightly scheduled classroom spaces. There has been an increasing demand to move some doctoral courses in education and geosciences to hybrid because faculty have found that this instructional format builds a community of learners who stay connected to course content and continue to be trackable outside the classroom discussions. 


\section{Starting a Digital Academy}

Offering an Academy is an effective way of helping groups of faculty learn how to design and teach hybrid courses. We believe the experiences and data presented here speak to the value of instituting a structured faculty development Academy that immerses participants in the hybrid teaching environment. Before instituting a Digital Academy, faculty developers should consider time commitment, faculty and administrative buy-in, transferability across technologies, portability across disciplines and courses, campus-specific factors, and sustainability over time.

\section{Time Investment}

The Academy does have significant time investments associated with its design and delivery. The initial two academies had a substantial time investment of over four hundred net hours as developers were considering all elements at once: content, delivery, faculty relations, and technologies.

As content has stabilized and the mode of delivery has been tested and proven, time commitment has diminished. However, over one academic year, faculty developers spend approximately 220 hours in researching and adding new ideas to content, delivering content, providing follow-up support, and assessing courses and students. Faculty spend about 50 to 60 hours a week attending the Academy (face-to-face and online), working on homework, and working on course development. Although this may seem like a huge time commitment for faculty developers, the net payoff is high compared to providing one-on-one consultations and a series of workshops with sporadic attendance where tracking of outcomes becomes difficult and faculty get distracted by other issues.

\section{Ensure Faculty and Administrative Buy-In}

Before engaging in course development efforts, faculty developers need to secure administrative buy-in and become aware of possible incentives such as course reductions, research support, or summer stipends. Faculty buy-in is also important for ensuring robust involvement and program growth. Providing student survey data along with research on the efficacy of hybrid and online courses helps to make the case for adoption. Over time, successful online instructors can be tapped to lead workshops within their departments or colleges to encourage the development of more courses. Without these key elements of support, sustaining training efforts can become an issue. 


\section{Transferability Across Technologies}

Traditional courses have common instructional tools; the same is true for hybrid courses. However, an Academy must consist of more than a series of application-specific how-to workshops. Sustainability is one reason; as we know, technologies constantly change, so what is usable for one semester may not be a viable or supported option in the next. The most significant reason to support hybrid teaching across technologies, however, is that using technology should not take precedence over achieving learning goals. Participants should first be asked to consider course learning objectives and goals and then to consider the technologies that will help achieve those goals. Faculty should also be encouraged to find what works, but not to become wedded to one technology. In addition, it is important to encourage the use of technologies that are supported by the institution through licensing and technical support.

\section{Portability Across Disciplines and Courses}

To create a "culture of use" (Brunk-Chavez \& Miller, 2009), Academy leaders need to build a "portable model simple and dynamic enough to be a framework for developing an Academy, but one that [does] not make up a completed, static structure" (p. 14). Some topics should remain common across all Academies, including syllabus reenvisioning, content planning and design, structured assessment, and need-based adoption of technologies. However, within this structure, flexibility needs to be provided for adaptations depending on the leaders' objectives and participants' needs. Another way to facilitate portability is to chunk all Academy content so that it is packaged in small, self-contained portions that can be reused and reshaped for future Academies.

\section{Campus-Specific Factors}

An integrated model, where pedagogical strategies and technological training coexist, is the necessary solution for enabling faculty to design hybrid content and interactions for students. Because of our focus on course redesign and pedagogy, the Academy is independent of specific learning management systems (the Academy has been delivered using WebCT 4.2, Blackboard 8.1, Moodle, and Sakai) or any other technologies, and is thus portable to other universities. For example, for an Academy delivered in Chile, our pre-Academy surveys indicated a strong preference for open source tools. Therefore, the Academy facilitators 
located and prepared recommendations for open source technologies that participants could use to engage their students in learning activities. The structure of the Academy allowed faculty developers to be flexible in meeting the needs of the local population.

\section{Sustainability}

For the Academy to sustain momentum across campus, it is imperative to have strong faculty buy-in and participation in terms of attendance and in the design and delivery of future Academies. While faculty developers often develop a strong sense of ownership of their "product," the key to sustainability is letting the product be reshaped by its users. Over time, the Academy has become largely faculty led, with ISS staff playing a support role in research and delivery. We find that content delivery by faculty colleagues is sometimes not perfect, but it can engage faculty participants at a deeper level.

\section{Assessment and Continuous Improvement}

Assessment and continuous improvement apply to both the Academy and the individual hybrid courses delivered. It is important that all faculty who are teaching hybrid courses conduct a learning outcomes analysis with an improvement focus. We encourage the forming of partnerships in Academies so participants look at one another's data and provide improvement-focused feedback. ISS staff, of course, help the faculty make changes to their course as requested and needed. We also encourage refresher workshops for all faculty who were involved in the Academy as participants and facilitators.

\section{Conclusion}

Training faculty in learning management technology and online and hybrid pedagogies can be a daunting task, and yet this is just what may be required to create a strong foundation of hybrid courses and wellversed, experienced hybrid instructors at any university. Increasingly diversified student populations, as well as growing enrollments, create an immediate demand for such training, though often the required paradigm shift in faculty pedagogy is ignored in the name of efficiency. The Digital Academy, an integrated model where technology training and practical teaching strategies coexist, is a solution for enabling faculty to create and deliver effective hybrid courses. 


\section{REFERENCES}

Brunk-Chavez, B., \& Miller, S. (2009). The hybrid academy: Building and sustaining a technological culture of use. In D. N. DeVoss, H. A. McKee, \& R. Selfe (Eds.), Technological ecologies and sustainability. Logan: Utah State University Press. Retrieved from http://ccdigitalpress.org/ebooks-andprojects/tes

Chickering, A., \& Ehrmann, S. (1996, October). Implementing the seven principles: Technology as lever. AAHE Bulletin, 49(2), 3-6. Retrieved from www.tlgroup.org/programs/seven.html

Cho, S. K., \& Berge, Z. L. (2002). Overcoming barriers to distance training and education. USDLA Journal, 16(1). Retrieved from www.usdla.org/html/ journal/JAN02_Issue/article01.html

Dudeney, G. (2001). The Internet and the language classroom. EIT Journal, $55(1)$. Retrieved from www.dudeney.com/consultants-e/webquests/ resources.html

Howe, N., \& Strauss, W. (2000). Millennials rising: The next great generation. New York, NY: Vintage.

Laird, P. G. (2003, May). Flexible design, development, and delivery: Using the e-course manual to simplify faculty transitions to online education. Paper presented at the Council for Christian Colleges and Universities Technology Conference, Jackson, TN.

National Center for Academic Transformation. (2005). Program in course redesign. Retrieved from www.thencat.org/PCR.htm

Palfrey, J., \& Gasser, U. (2008). Born digital: Understanding the first generation of digital natives. New York, NY: Basic Books.

Roberts, G. R. (2005). Technology and learning expectations of the Net generation. In D. Oblinger \& J. Oblinger (Eds.), Educating the Net generation. Boulder, CO: Educause. Retrieved from www.educause.edu/Resources/ EducatingtheNetGeneration/TechnologyandLearningExpectati/6056

Sands, P. (2002). Inside outside, upside downside: Strategies for connecting online and face-to-face instruction in hybrid courses. Teaching with Technology Today, 8(6). Retrieved from www.uwsa.edu/ttt/articles/ sands2.htm

Selber, S. (2004). Multiliteracies for a digital age. Urbana: Southern Illinois University Press.

Sharp, V. (2005). Integrating technology into classroom teaching. New York, NY: McGraw-Hill.

Tapscott, D. (1999) Growing up digital: The rise of the Net generation. New York, NY: McGraw-Hill. 